was of a bright-red colour, and coated with a thin layer of catamenial fluid. Both Fallopian tubes were red and turgid, and the interior of the left was filled with menstrual fluid; but nothing in the form of a Graafian vesicle could be detected in the tube. The appearances now described have been accurately represented in a drawing made from the parts within two hours after they came into the author's (Dr. R. Lee) possession.

Dr. Robert Lee concludes, in the most able paper, from which I have made the above selections, "that it is not to the influence of the uterus that we are to attribute all the changes which take place in the mammæ and uterine system at the period of puberty, but that all the phenomena of menstruation depend upon, or are connected with, some change in the Graafian vesictes, in consequence of which an opening is formed in their peritoneal and proper coats." "Whether an entir'e vosicle, or only the fluid if contains, escape through this opening at the period of menstruation," he adds, "further observation may hereafter determine."

The cases related by $\mathrm{Dr}$. Gendrin, in the "Traité Philosophique de Médecine Pratique," published in the year 1839, may be thus briefly noticed:-

In the first case the left ovarium was vascular, and in the middle was an aperture about a line in diameter, with an irregular margin; its cavity would have contained a hemp-seed; its walls were red; and it was obviously a ruptured Graafian vesicle.

In the second case a small circular ragged opening led to a cavity about two lines in diameter, its walls being of a bright-red colour.

In the fourth case the right ovary had an aperture a line and a half in diameter, leading to a small cavity with rascular parietes.

M. Negrier has also related similar cases which have come under his observation.

It is thus proved beyond doubt that neither Dr. Power nor Mr. Girdwood are entitled to the praises so lavishly bestowed upon them by Dr. Grant, and that if $D r$. Grant was ignorant of the observations and dissections of those distinguished physiologists whose opinions have been above stated, he ought not to have stood sponsor to a paper of the merits of which he could not be a judge.

Knowing the interest which you at all times take in seeing justice done to those against whom any unfair advantage has been taken, I am sure you will kindly insert this note in your valuable journal. I am, Sir,

A. B. C.

The cause of the right arm or right leg being stronger is congenital, depending on the more perfect development. $-D r K n o x$,

\section{AFFECTION OF THE HEAD FOLLOWING SCARLATINA.}

BLEEDING.

To the Editor of The LanceT.

SIr,-I shall feel much obliged by your inserting the following case in your truly valuable periodical :-

John Cooke, ten years of age, of a rather delicate appearance, had scarlatina very favourably about five weeks ago; some days after his recovery slight dropsical swellings ensued, which were removed by the administration of some active purgatives. On Monday, March 13th, I was informed that he was taken dangerously ill, and my immediate attendance was requested. I was, however, prevented from seeing him until the next morning, when my patient appeared as follows :-He was totally blind in both eyes; the pupils were rather contracted, but quite immoveable, even when exposed to the glare of a strong light; the face was swollen, and of a death-like paleness; no particular heat either of the head or temples; the pulse was very quick, feeble, and irregular; he was exceedingly lestless, in a state bordering on stupor or delirium, with occasional intervals of consciousness. Thus, he was enabled to state that he could not distinguish the slightest object, not even the light of a candle, and he complained of great pain all over the head. Soon after answering my questions he became delirious. The parents stated that on the evening before the boy suddenly complained of pain in the head; that he was removed to his bed, that shortly after he could scarcely distinguish the figures on the bed-curtains, and that in half an hour he became totally blind. This was at about six o'clock. At twelve o'clock he had a convulsive fit, foaming at the mouth, the mouth drawn towards the eye with gnashing of the teeth. Coma followed, attended with a snorting so loud as to be heard at the adjoining house. In this comatose state he continued until about eight o'clock on the following morning (about three hours before I called) when a similar fit recurred, only of longer duration. I may here observe that a purgative containing calomel had been sent on the night before, and had acted very powerfully, and that a large blister had been applied to the nape of the neck, which was discharging very freely.

Considering the case to be one of the most dangerous description, I at once bled the boy to abont twenty-five ounces. After the first twelve ounces had been abstracted the pulse slightly rose, and he became more composed, and at the conclusion the respiration was far more natural, and the patient shortly sunk into a deep sleep; a sleep very different, the parents stated, to that he had previously experienced. I ordered the head to be shaved, and a large blister to be ap. 
plied to the entire scalp, and three grains of / selves upon the attention of foreign chemists. calomel to be administered every three bours. I saw my patient on the following morning at about eight o'clock, ànd found that both rision and consciousness were perfectly restored, and that every bad symptom had entirely subsided. The blood was more than six parts serum; the crassamentum was slightly cupped, and very firm. I have since visited him several times, and he is daily improving. I am anxions to report this case, because I feel confident that its successful issue was entirely owing to the free abstraction of blood. I should not certainly have ventured upon so bold a measure but for the interesting case detailed by Dr. Marshall Hall about eighteen months ago in THE LANCET, I am, Sir, your very obedient servant,

Tywardreatis, Cornwall,

W. TAyler. March 20, 1843.

\section{EFFECT OF ALCOHOL ON THE SYSTEM.}

To the Editor of THE LANCET.

Sir,-Although I do not consider that the opposite of what Liebig has inferred in re. ference to the infuence and condition of alcohol in the system has been proved, it may not perhaps be going too far to say that his deductions are not conclusive, and that the subject still requires accurate investigation. As his commentator, Mr. Ancell, in the pages of The LanceT, seems to have a different opinion, it may not be out of place here to recur to the admirable experiments of Dr. Prout, made in 1813, which have certainly not been supplanted by any of the observations of foreign chemists; and it were to be wished that Englishmen would attend rather more to what has been done in their own country. The controversy at present waging between Liebig and Dumas must make our countrymen pause before setting aside the experiments made in this country upon organic bodies, and may ultimately convince them that the methods of investigation pointed ont by $\mathrm{Dr}$. Prout upwards of twenty years ago, are only beginning to force themI think, Sir, that you would confer a great obligation on your readers by a reprint of Dr. Prout's paper on Respiration, published in the 2 nd vol., p. 328, and 4th vol., p. 331, of the "Annals of Philosophy." The passage referring to the effect of alcohol upon respiration is to the following effect:-Alcohol and all liquors containing it which he tried, he found to have the remarkable property of diminishing the quantity of carbonic acid in the expired air much more than anything else which he made the subject of experiment. When porter was taken at dinner the quantity was always much reduced below the natural standard, while the reverse was the case when water was taken. This induced him to extend his experiments, the result of which was, that alcohol in every state, and in every quantity, uniformly lessens in a greater or less degree, the quantity of carbonic acid elicited, according to the quantity and circumstances in which it is taken. When taken on an empty stomach its effects were most remarkable, the depression being almost instantaneous; after a short time the powers of the constitution appear to rally, and the quantity rapidly increases; then it sinks again, and afterwards rises slowly to the standard. On a full stomach, as after dinner, the effects of vinous liquors are very slow, but no less sure and remarkable. $\mathbf{D r}$. Prout has even thought them more permanent. As long as the effects of alcohol are perceptible so long is the quantity of carbo. nic acid gas emitted below the standard. With Dr. Prout these effects went off with frequent yawnings, and with a sensation as if he had just awoke from sleep. Under these circumstances the quantity is much above the standard, and hence it may be concluded that the system is then freeing itself from the carbon retained by the influence of the alcohol. The effect of strong tea is somewhat similar.

The following table is exceedingly interesting. The first column gives the hours of experiment; the second the standard percentage of carbonic acid at these hours; the third the observed quantity; and the fourth the state of the pulse :-

\begin{tabular}{|c|c|c|c|c|c|}
\hline \\
\hline $\begin{array}{l}\text { H. } \\
\text { a.m }\end{array}$ & M. & & & & \\
\hline 114 & & 4.0 & 4.0 & 70 & Before taling wine. \\
\hline 121 & 10 & 4.05 & 3. & 72 & Five minutes after taking three ouncss. \\
\hline $12 \vdots$ & 30 & 4.0 & 3.4 & 76 & ZFramole of ocillation \\
\hline $\mathbf{1}$ & $\mathbf{0}$ & 3.95 & 3.1 & 78 & le of oscillation, \\
\hline $\mathbf{I}$ & 25 & 3.86 & 3.1 & 78 & \\
\hline 3 & $\mathbf{0}$ & 3.66 & 3. & 84 & Twenty minutes after a walk and dinner. \\
\hline $\mathbf{3}$ & 30 & 3.6 & 3.1 & 78 & \\
\hline 3 & 55 & 3.56 & $\mathbf{3}$. & 74 & Ten minutes after taking half a pint of wine. \\
\hline 4 & $\mathbf{5}$ & 3.54 & 3. & 78 & Slight effects of ditto observable. \\
\hline 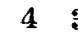 & 30 & 3.50 & 2.70 & 78 & Very strong effects of ditto, as vertiga. \\
\hline 5 & $\mathbf{0}$ & 3.46 & 2.90 & 76 & \\
\hline 8 & 5 & 3.32 & 3.60 & 76 & Effects gone off; frequent yawnings. \\
\hline
\end{tabular}
No. 1022 ,

The standard was resumed 5h. $45 \mathrm{~min}$. after having taken the wine. 